\title{
Health-related quality of life in patients with primary open-angle glaucoma. An Italian multicentre observational study
}

Irene Floriani, ${ }^{1, \dagger}$ Luciano Quaranta, ${ }^{2, \dagger}$ Eliana Rulli, ${ }^{1}$ Andreas Katsanos, ${ }^{2}$ Luigi Varano, ${ }^{3}$ Paolo Frezzotti, ${ }^{4}$ Gemma C. M. Rossi, ${ }^{5}$ Luciana Carmassi, ${ }^{6}$ Teresa Rolle, ${ }^{7}$ Roberto Ratiglia, ${ }^{8}$ Stefano Gandolfi, ${ }^{9}$ Maurizio Fossarello, ${ }^{10}$ Maurizio Uva, ${ }^{11}$ Lital Hollander, ${ }^{1}$ Davide Poli ${ }^{1}$ and Federico Grignolo ${ }^{7}$ on behalf of the Italian Study Group on QoL in glaucoma*

${ }^{1}$ IRCCS Istituto di Ricerche Farmacologiche Mario Negri, Milan, Italy

${ }^{2}$ University of Brescia, Brescia, Italy

${ }^{3}$ University 'Magna Graecia', Catanzaro, Italy

${ }^{4}$ University of Siena, Siena, Italy

${ }^{5}$ IRCCS - San Matteo Polyclinic, Pavia, Italy

${ }^{6}$ IRCCS - Istituto Auxologico Italiano, Milan, Italy

${ }^{7}$ University of Turin, Turin, Italy

${ }^{8}$ IRCCS - Ca'Granda Foundation - Ospedale Maggiore Policlinico, University of Milan, Milan, Italy

${ }^{9}$ University Hospital of Parma, Parma, Italy

${ }^{10}$ University Hospital 'San Giovanni di Dio', Cagliari, Italy

${ }^{11}$ University Hospital 'Policlinico Vittorio Emanuele', Catania, Italy

\begin{abstract}
.
Purpose: As a progressive condition, glaucoma may impair health-related quality of life (HRQoL), due to vision loss and other factors. This study evaluated HRQoL in a cohort of patients treated for primary open-angle glaucoma (POAG) and assessed its association with clinical features.

Methods: This was an Italian, multicentre, cross-sectional, observational study with the subgroup of newly diagnosed patients with POAG prospectively followed up for one year. Patients with previous or new diagnosis (or strong clinical suspicion) of POAG aged $>\mathbf{1 8}$ years were considered eligible. Information was collected on demographic characteristics, medical history, clinical presentation and POAG treatments. HRQoL was measured using the 25-item National Eye Institute Visual Function Questionnaire (NEI-VFQ-25) and Glaucoma Symptom Scale (GSS). Subscale and total scores were obtained and a Pearson correlation coefficient between instruments' scores calculated.

Results: A total of 3227 patients were enrolled from 2012 to 2013 and 3169 were analysed. Mean age was 66.9 years. A total of $\mathbf{9 3 . 8 \%}$ had a previous diagnosis (median duration: $\mathbf{8 . 0}$ years). Median values for mean deviation and pattern standard deviation were 3.9 and 3.6 dB, respectively. Mean scores on most subscales of the NEI-VFQ-25 exceeded 75.0 and mean GSS subscale scores ranged between 70.8 and 79.7 (with a total mean score of 74.8). HRQoL scores on both scales were significantly inversely associated with POAG severity.

Conclusion: In this large sample of Italians treated for POAG, disease severity was limited and HRQoL scores were high. QoL decreased with advancing disease severity. These findings confirm the role of vision loss in impairing QoL in POAG, underlying the importance of timely detection and appropriate treatment.
\end{abstract}

Key words: GSS - NEI-VFQ-25 - observational study - primary open-angle glaucoma - quality of life

(๑) 2015 Acta Ophthalmologica Scandinavica Foundation. Published by John Wiley \& Sons Ltd

doi: 10.1111/aos. 12890

*Italian Study Group on QoL in glaucoma, see Appendix.

$\dagger$ These authors contributed equally to this work.

2014 ARVO Annual Meeting, 4-8 May 2014, Orlando, Florida (US); 11th EGS Congress - Nice (France), 7-11 June 2014. 


\section{Introduction}

Glaucoma is a leading cause of irreversible visual loss worldwide (Giangiacomo 2009). Data from population-based surveys indicate that $1.86 \%$ of adults $\geq 40$ years old has glaucoma, which equates to 60 million people worldwide being affected and 8.4 million being bilaterally blind (Giangiacomo 2009; Quigley 2011). Of several types of glaucoma, primary open-angle glaucoma (POAG) is the most common. Populations of European ancestry are particularly affected (Giangiacomo 2009; Kwon et al. 2009). In Italy, a population-based survey reported a POAG prevalence of $1.4 \%$ in a population of 5000 adults of rural northern Italy (Bonomi et al. 1998).

As a chronic and progressive condition, POAG can significantly affect quality of life (QoL). Visual impairment, associated with limitation of daily function and loss of autonomy, may lead to or exacerbate depression, loneliness and anxiety (Dodds 1991; Hinds et al. 2003), especially in the elderly (Baker \& Winyard 1998).

However, other non-visual factors, such as distress caused by the knowledge of having a blinding illness, cost of treatment or problems and adverse reactions to glaucoma therapies, have also been frequently implicated as factors negatively impacting QoL in these patients (Stuck et al. 1999; Odberg et al. 2001a; Spaeth et al. 2006).

Health-related QoL (HRQoL) measures can be indicative of the diseaserelated burden experienced by the patient, and its importance is increasingly recognized. In fact, the very aim of glaucoma management is the patient's autonomy and preservation of QoL at a sustainable cost (European Glaucoma Society 2014).

Compared to the state of evidence on the impact of other chronic diseases on QoL, the existing literature on glaucoma-related QoL is limited (Mills et al. 2009). Moreover, the relative role of different factors in affecting QoL in patients with POAG merits investigation and requires a sufficiently numerous patient population.

The investigators of the Italian Study Group on QoL in Glaucoma have designed a study with both a cross-sectional and a prospective part. The aim of the cross-sectional part was the evaluation of HRQoL in a large cohort of patients with POAG, and the assessment of the contribution of socio-demographic and clinical features. Vice versa, the prospective part aimed to assess the changes in QoL measures over 12-month follow-up. This first report describes the study design, sample characteristics and overall results on QoL of the cross-sectional cohort study.

\section{Methods}

This was an Italian, multicentre observational study. In an effort to capture a cohort representative of the population of Italian patients with POAG, the ophthalmic centres invited to participate comprised of both academic and non-academic institutions with a nationwide geographical distribution.

The study was conducted in accordance with the tenets of the Declaration of Helsinki and the Guidelines for Good Clinical Practice. The institutional review board of each participating centre approved the protocol. The participants gave informed consent after the nature and purpose of the survey were fully explained. Data were handled according to current Italian legislation on observational studies.

\section{Patients and procedures}

Patients with a previous or new diagnosis (or strong clinical suspicion) of

Table 1. Participating centre distribution and accrual.

\begin{tabular}{|c|c|c|c|c|}
\hline Centre & Patients & $\begin{array}{l}\text { Academic/ } \\
\text { non-academic }\end{array}$ & City & $\begin{array}{l}\text { Geographical } \\
\text { region }\end{array}$ \\
\hline University of 'Magna Graecia' & 419 & Academic & Catanzaro & South/Isles \\
\hline $\begin{array}{l}\text { A.O.U. Senese Ospedale Santa } \\
\text { Maria delle Scotte, Università } \\
\text { di Siena }\end{array}$ & 336 & Academic & Siena & Centre \\
\hline $\begin{array}{l}\text { Fondazione IRCCS Istituto di } \\
\text { Ricovero e Cura a Carattere } \\
\text { Scientifico Policlinico San } \\
\text { Matteo }\end{array}$ & 294 & Non-academic & Pavia & North-west \\
\hline $\begin{array}{l}\text { IRCCS Istituto di Ricovero e } \\
\text { Cura a Carattere Scientifico } \\
\text { Istituto Auxologico Italiano }\end{array}$ & 265 & Non-academic & Milano & North-west \\
\hline University of Torino & 253 & Academic & Torino & North-west \\
\hline University of Brescia & 205 & Academic & Brescia & North-west \\
\hline $\begin{array}{l}\text { Fondazione IRCCS Istituto di } \\
\text { Ricovero e Cura a Carattere } \\
\text { Scientifico Ca' Granda } \\
\text { Ospedale Maggiore } \\
\text { Policlinico }\end{array}$ & 204 & Academic & Milano & North-west \\
\hline A.O.U. di Parma & 200 & Academic & Parma & North-east \\
\hline $\begin{array}{l}\text { A.O.U. Cagliari - Ospedale } \\
\text { Civile San Giovanni di Dio }\end{array}$ & 183 & Academic & Cagliari & South/Isles \\
\hline $\begin{array}{l}\text { A.O.U. 'Policlinico Vittorio } \\
\text { Emanuele' P.O. Gaspare } \\
\text { Rodolico }\end{array}$ & 126 & Academic & Catania & South/Isles \\
\hline A.O.U. 'Ospedale Maggiore' & 114 & Academic & Trieste & North-east \\
\hline $\begin{array}{l}\text { A.O. Arcispedale Santa Maria } \\
\text { Nuova-IRCCS }\end{array}$ & 107 & Non-academic & Reggio Emilia & North-east \\
\hline $\begin{array}{l}\text { Università Tor Vergata, } \\
\text { Fondazione Policlinico Tor } \\
\text { Vergata }\end{array}$ & 100 & Academic & Rome & Centre \\
\hline A.O. S. Paolo & 100 & Academic & Milan & North-west \\
\hline A.O.U. Policlinico & 98 & Academic & Bari & South/Isles \\
\hline $\begin{array}{l}\text { Ospedale Clinicizzato SS. } \\
\text { Annunziata }\end{array}$ & 64 & Non-academic & Chieti & South/Isles \\
\hline $\begin{array}{l}\text { A.O.U. Policlinico S. Orsola } \\
\text { Malpighi }\end{array}$ & 36 & Academic & Bologna & North-east \\
\hline A.O. di Desenzano del Garda & 30 & Non-academic & $\begin{array}{l}\text { Desenzano } \\
\text { del Garda }\end{array}$ & North-west \\
\hline $\begin{array}{l}\text { Dipartimento SPES Università } \\
\text { del Molise }\end{array}$ & 20 & Academic & Campobasso & South/Isles \\
\hline $\begin{array}{l}\text { IRCCS AOU San Martino - } \\
\text { IST }\end{array}$ & 15 & Academic & Genova & North-west \\
\hline
\end{tabular}


Table 2. Socio-demographic characteristics of the eligible patients $(N=3169)$.

\begin{tabular}{lr}
\hline Age - years & \\
Mean $(\mathrm{SD})$ & $66.9(12.1)$ \\
Min-max values & $18.6-100.6$ \\
Female sex $-N(\%)$ & $1578(49.8)$ \\
Race $-N(\%)$ & $3147(99.3)$ \\
Caucasian & $16(0.5)$ \\
Black & $6(0.2)$ \\
Asian & \\
Educational $-N(\%)^{*}$ & $24(0.8)$ \\
Illiterate & $917(29.0)$ \\
Primary school & $899(28.4)$ \\
Secondary school & $976(30.8)$ \\
High school & $352(11.1)$ \\
University degree & \\
Housing status $-N(\%)^{*}$ & $2520(79.5)$ \\
In family & $534(16.9)$ \\
Alone & $114(3.6)$ \\
With other people & \\
Employment status $-N(\%)^{*}$ & $1910(60.3)$ \\
Retired & $749(23.6)$ \\
Active & $410(12.9)$ \\
Housewife & $67(2.1)$ \\
Unemployed & $25(0.8)$ \\
Student & $7(0.2)$ \\
Other & \\
\hline
\end{tabular}

$\mathrm{SD}=$ standard deviation min $-\max =$ minimum - maximum

* One missing value.

Table 3. Clinical characteristics of the eligible patients $(N=3169)$.

\begin{tabular}{lc}
\hline At first diagnosis $-N(\%)$ & $197(6.2)$ \\
Years from diagnosis* & \\
Median $(\mathrm{Q} 1, \mathrm{Q} 3)$ & $0.0(4.0,13.0)$ \\
Min-max values & $3022(95.4)$ \\
Bilateral glaucoma $-N(\%)$ & \\
Mean deviation - decibel ${ }^{*}$ & $-3.90(-8.50,-1.55)$ \\
Median $(\mathrm{Q} 1, \mathrm{Q} 3)$ & -42.35 to +3.70 \\
Min-max values & \\
PSD - decibel & $3.60(2.01,6.65)$ \\
Median $(\mathrm{Q} 1, \mathrm{Q} 3)$ & $0.33-25.80$ \\
Min-max values & \\
Visual Field Index $-\%{ }^{*}$ & $93.0(80.5,97.5)$ \\
Median $(\mathrm{Q} 1, \mathrm{Q} 3)$ & $0-100$ \\
Min-max values & \\
Severity of disease $-N(\%)^{\dagger, *}$ & $12(0.4)$ \\
Stage 0 & $394(12.6)$ \\
Borderline & $576(18.4)$ \\
Stage 1 & $657(21.0)$ \\
Stage 2 & $477(15.3)$ \\
Stage 3 & $431(13.8)$ \\
Stage 4 & $575(18.4)$ \\
Stage 5 & \\
\hline
\end{tabular}

* In previously diagnosed patients only. One value missing.

${ }^{\dagger}$ Worst eye in case of bilateral glaucoma.

Missing values.
POAG were approached during regular clinic visits and screened for participation in this study. To be eligible for participation, patients needed to be 18 years or older and to be able to comprehend and reply to the self-administered study instruments. Concurrent asymmetry $>2$ in the absence of other neurodegenerative conditions. The presence of typical glaucomatous visual field defects was not a prerequisite for inclusion if clinical judgment was strongly in favour of glaucoma (e.g. high IOP, optic disc haemorrhages, retinal nerve fibre layer defects) (Topouzis et al. 2008).

Eligible patients underwent a comprehensive ocular examination and treatment was started or continued, as clinically indicated. Demographic characteristics, medical and ophthalmic history, and information on surgical and medical treatments of POAG were collected and QoL questionnaires administered. Glaucoma severity was classified in all patients according to Glaucoma Staging System 2 (Brusini \& Filacorda 2006). Only reliable visual field data (i.e. visual fields were considered reliable if false-positive responses were fewer than $15 \%$ and a clear blind spot could be seen in the visual field printouts, threshold value $<10$ decibel $[\mathrm{dB}])$ were included in the analysis.

\section{Study instruments}

Study HRQoL instruments comprised of the validated Italian versions of the 25-item National Eye Institute Visual Function Questionnaire (NEI-VFQ-25) (Rossi et al. 2003) and the Glaucoma Symptom Scale (GSS) questionnaire (Rossi et al. 2013).

GSS (Lee et al. 1998), a glaucomaspecific instrument, includes 10 items grouped into two domains (Symp-6 for non-visual symptoms and Func-4 for visual symptoms). Each eye is assessed separately for the presence of ten specific symptoms, using a 0 100 scale, where zero represents the highest grade of disturbance and 100 indicates the symptom's absence. The subscale score is the unweighted average of subscale score of each eye. Similarly, the total GSS score is the mean of the 10 subscale scores. Hence, GSS scores can be calculated as average between the two eyes or for each eye separately.

NEI-VFQ-25 is a self-administered, 25-item, 12-subscale questionnaire designed to measure vision-dependent function and used to assess impact of different of ocular conditions on HRQoL (Mangione et al. 2001). Each subscale receives a score of 0-100, where higher scores reflect better participation in another clinical trial was considered an exclusion criterion.

Patients were considered eligible for inclusion if they had typical glaucomatous optic nerve head damage, that is focal or generalized (or both) neuroretinal rim thinning or cup/disc ratio 
Table 4. Previous and concomitant antiglaucoma treatments $(N=3169)$.

\begin{tabular}{|c|c|}
\hline \multicolumn{2}{|l|}{ Previous treatment $-N(\%)^{*}$} \\
\hline None & $73(2.5)$ \\
\hline Only medical & $2113(71.1)$ \\
\hline Only surgical & $96(3.2)$ \\
\hline Both medical and surgical & $689(23.2)$ \\
\hline \multicolumn{2}{|l|}{ Type of previous non-medical treatment $-N(\%)^{*}$} \\
\hline Trabeculectomy & $448(57.1)$ \\
\hline Laser (ALT, SLT) & $397(50.6)$ \\
\hline Deep sclerectomy & $19(2.4)$ \\
\hline Viscocanalostomy & $3(0.4)$ \\
\hline Other & $21(2.7)$ \\
\hline \multicolumn{2}{|l|}{ Number of previous surgeries per patient $-N(\%)^{\dagger}$} \\
\hline 1 & $687(87.5)$ \\
\hline 2 & $93(11.8)$ \\
\hline 3 & $5(0.6)$ \\
\hline \multicolumn{2}{|l|}{ Type of previous antiglaucoma drugs $-N(\%)^{*}$} \\
\hline Prostaglandins & $1440(51.4)$ \\
\hline Carbonic anhydrase inhibitor-beta-blocker combination & $691(24.7)$ \\
\hline Beta-blockers & $691(24.7)$ \\
\hline Prostaglandin-beta-blocker combinations & $559(20.0)$ \\
\hline Carbonic anhydrase inhibitors & $326(11.6)$ \\
\hline Alpha-agonist-beta-blocker combinations & $130(4.6)$ \\
\hline Parasympathomimetic drug & $105(3.7)$ \\
\hline Others & $7(0.2)$ \\
\hline \multicolumn{2}{|l|}{ Number of previous antiglaucoma drugs per patient $-N(\%)^{*}$} \\
\hline 1 & $1742(62.2)$ \\
\hline 2 & $887(31.7)$ \\
\hline $3-5$ & $172(6.1)$ \\
\hline Use of concomitant drugs $-N(\%)$ & $2197(69.6)$ \\
\hline \multicolumn{2}{|l|}{ Type of concomitant drugs $-N(\%)$} \\
\hline Antihypertensive drugs & $1538(48.5)$ \\
\hline Statins & $587(18.5)$ \\
\hline Endocrine drugs & $483(15.2)$ \\
\hline Antiaggregant drugs & $406(12.8)$ \\
\hline Diuretics & $168(5.3)$ \\
\hline Antiarrhythmics & $163(5.1)$ \\
\hline Anticoagulant drugs & $131(4.1)$ \\
\hline Cardiovascular drugs & $60(1.9)$ \\
\hline Other drugs & $363(11.5)$ \\
\hline \multicolumn{2}{|l|}{ Number of concomitant drugs per patient $-N(\%)^{\S}$} \\
\hline 1 & $999(45.5)$ \\
\hline $2-3$ & $982(44.7)$ \\
\hline $4-7$ & $216(9.8)$ \\
\hline
\end{tabular}

ALT $=$ Argon laser trabeculoplasty; SLT $=$ Selective laser trabeculoplasty.

* Already diagnosed patients only $(n=2972)$.

${ }^{\dagger}$ Patients with previous surgery only $(n=785)$.

* Patients with previous medical treatment only $(N=2802)$.

${ }^{\S}$ Patients with concomitant drugs only $(n=2197)$.

vision-related QoL. The global score is the mean of the 11 subscale scores, excluding the general health item.

\section{Statistical consideration}

In Italy, there are currently approximately 500000 patients with POAG managed in 50 specialized glaucoma centres (Cedrone et al. 2008). Based on this assumption, a cohort of at least 3000 patients enrolled by approximately 20 ophthalmic centres was considered representative of the Italian population of patients with POAG.
Descriptive summary statistics are presented as mean, standard deviation, minimum and maximum values, and/or median, 25th and 75th percentiles (Q1, Q3), for continuous variables. Absolute frequency and percentage were used for categorical variables. The Spearman rank correlation test was used to study the strength of correlation between each single subscale and the mean total scores of the two study instruments. Correlation coefficients $>0.5$ were considered large, $0.5-0.3$ moderate, $0.3-0.1$ small and smaller than 0.1 insubstantial (Cohen 1988).
For all analyses, we have considered patients as unit of analysis; for GSS Questionnaire, the mean of the two eyes was used.

The association between QoL subscales and the severity of glaucoma, as expressed by the Glaucoma Staging System 2, was analysed by means of linear regression models.

All analyses were performed with the SAS software version 9.1.3 (SAS Institute Inc, NC, USA).

\section{Results}

Twenty academic and non-academic ophthalmic centres participated in this study. Table 1 illustrates the geographical distribution of the centres and the accrual by Italian region. From March 2012 until July 2013, 3227 patients were enrolled in these centres. The information provided by fifty-eight patients $(1.8 \%)$ was incomplete. Therefore, the statistical analysis was performed on data from 3169 study participants.

Tables 2 and 3 summarize the sociodemographic and clinical characteristics of the participants. A total of $49.8 \%$ of participants were females, and mean age was 66.9 years (SD 12.1). A total of $93.8 \%$ patients had a previous diagnosis of POAG with median duration of 8.0 years. Median values (Q1, Q3) for mean deviation (MD), pattern standard deviation (PSD) and visual field index (VFI) were

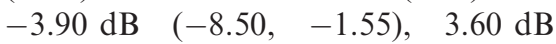
$(2.01,6.65)$ and 93.0 (80.5, 97.5), respectively. Severity assessment, available for 3122 patients, showed mild disease (Stage $\leq 1$ ) in $31.4 \%$ patients and advanced disease (stage $\geq 4$ ) in $32.2 \%$. For patients with stage 4 disease, the range of MD values was -15 to $-21 \mathrm{~dB}$ and the range of PSD values was 14 to $20 \mathrm{~dB}$. For patients with stage 5 disease, the MD values were $<-21 \mathrm{~dB}$ and the PSD values $>20 \mathrm{~dB}$.

A total of $97.5 \%$ of patients had received previous medical and/or surgical treatment for glaucoma. Previous and concomitant treatments are presented in Table 4.

Overall, $41.2 \%$ patients reported at least one risk factor for glaucoma, the most common being positive family history $(35.6 \%)$. The most frequent self-reported comorbidities included systemic hypertension $(53.2 \%)$ and hyperlipidaemia $(26.2 \%)$. Risk factors 
FAMILY HISTORY

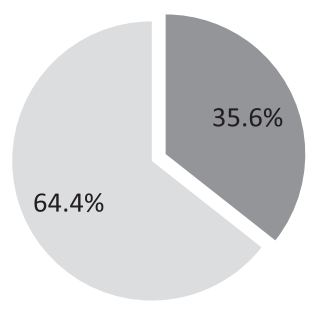

VASOSPASM

$1.8 \%$

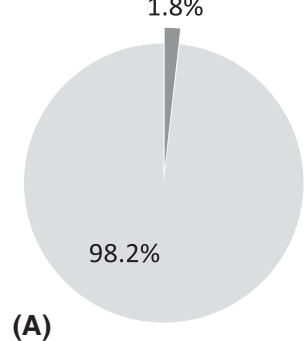

(A)

\section{HYPERTENSION}

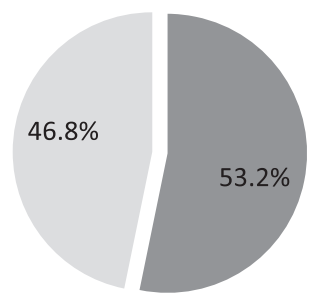

HYPOTHIROIDISM

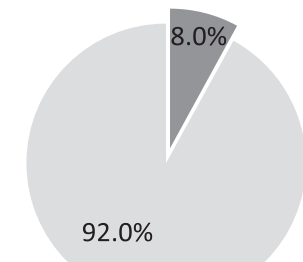

(B)
DIABETES

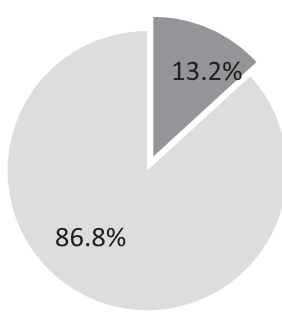

OTHERS

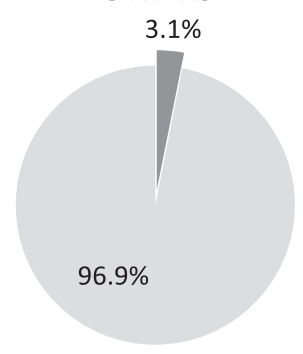

HYPERLIPIDEMIA

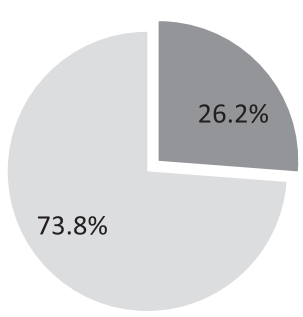

HYPOTENSION

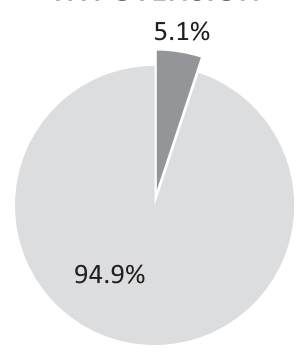

HEADACHE

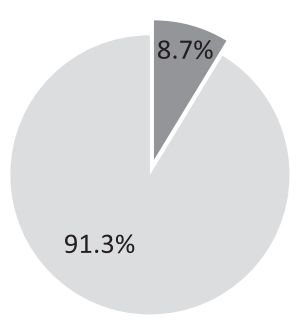

between most subscale and total scores and the severity of glaucoma, as expressed by the Glaucoma Staging System 2 (Figs 2 and 3), with the exception of the GSS Symp-6 score for nonvisual disturbances $(p=0.1396)$. The NEI-VFQ-25 total mean score was reduced from 92.7 in patients with glaucoma stage 0-74.3 in patients with stage 5 disease. The worst affected domains were 'general vision' (69.2 in stage $0-51.3$ in stage 5 ), near activities (94.4-71.0) and driving (93.6-68.3).

\section{Correlation between HRQoL instruments}

Table 7 summarizes the results of the correlation analysis. Overall, specific GSS subscales showed correlation with NEI-VFQ-25 subscales designed to capture similar constructs, but did not correlate with subscales describing different HRQOL domains. The Symp-6 score highly correlated with the NEIVFQ-25 pain subscale $(r=0.624)$, which assesses the impact of ocular pain or discomfort. Func-4 score showed a large correlation with the distant activities subscale $(r=0.533)$.

\section{Discussion}

The issue of QoL in patients with glaucoma has gained considerable interest in recent years (Glen et al. 2011), but the amount and quality of information remain incomplete (Mills et al. 2009).

This is partially due to the fact that the objective indicators currently employed to describe glaucoma-related visual damage, such as visual fields, may fail to fully capture the negative impact of the disease and its treatment on patient perception of well-being (Odberg et al. 2001b). In fact, the assessment of the degree of glaucomatous visual field loss that can cause significant deterioration in a patient's ability to function independently (Varma et al. 2010) is not straightforward. Moreover, HRQoL in glaucoma may be influenced by multiple factors more generally related to the burden of the disease and its treatments.

A better understanding of patients' HRQoL can help clinicians in customizing disease management and tailoring treatment and promote guidelines regarding patients' preferences, daily routine and safety (Glen et al. 2011). We assessed HRQoL and visionrelated QoL in a large sample of scores for GSS. The total mean score symptoms domain Symp-6 was 74.9.

Most scales of both questionnaires showed a ceiling effect (i.e. clustering of scores at the upper level), with a consequent reduction in their discrimination power.

\section{HRQoL and glaucoma severity}

A clear and highly significant association $(p<0.001)$ has been observed 
Table 5. Distribution of National Eye Institute Visual Function Questionnaire (NEI-VFQ-25) scores.

\begin{tabular}{|c|c|c|c|c|c|c|c|c|c|}
\hline Scale & $N$ & Mean (SD) & Min & Q1 & Median & Q3 & Max & Floor $(\%)$ & Ceiling $(\%)$ \\
\hline General health & 3165 & $56.7(17.9)$ & 0 & 47.5 & 60.0 & 65.0 & 100 & 0.9 & 1.6 \\
\hline General vision & 3164 & $60.4(16.3)$ & 0 & 50.0 & 60.0 & 70.0 & 100 & 0.1 & 1.0 \\
\hline Ocular pain & 3165 & $77.7(20.2)$ & 0 & 62.5 & 75.0 & 100 & 100 & 0.2 & 26.4 \\
\hline Near activities & 3165 & $81.9(20.1)$ & 0 & 70.8 & 87.5 & 100 & 100 & 0.1 & 26.9 \\
\hline Distance activities & 3166 & $87.7(17.4)$ & 0 & 83.3 & 95.8 & 100 & 100 & 0.2 & 38.7 \\
\hline V-S social functioning & 3164 & $94.1(13.9)$ & 0 & 91.7 & 100 & 100 & 100 & 0.2 & 74.8 \\
\hline V-S mental health & 3165 & $77.4(20.8)$ & 0 & 70.0 & 85.0 & 90.0 & 100 & 0.3 & 8.0 \\
\hline V-S role difficulties & 3159 & $87.8(20.5)$ & 0 & 81.2 & 100 & 100 & 100 & 0.9 & 56.4 \\
\hline V-S dependency & 3156 & $92.0(19.0)$ & 0 & 93.8 & 100 & 100 & 100 & 0.6 & 74.1 \\
\hline Driving & 2319 & $81.0(24.3)$ & 0 & 75.0 & 87.5 & 100 & 100 & 4.3 & 33.2 \\
\hline Colour vision & 3135 & $94.8(15.3)$ & 0 & 100 & 100 & 100 & 100 & 0.4 & 86.9 \\
\hline Peripheral vision & 3159 & $85.7(22.0)$ & 0 & 75.0 & 100 & 100 & 100 & 0.4 & 63.2 \\
\hline Global & 3166 & $83.6(15.1)$ & 0.4 & 79.2 & 89.9 & 93.4 & 100 & 0.1 & 0.2 \\
\hline
\end{tabular}

SD, Standard deviation; Min, minimum value; Max, maximum value; Q1, 25th percentile; Q3, 75th percentiles; V-S, Vision specific.

Table 6. Distribution of Glaucoma Symptom Scale (GSS) Questionnaire scores.

\begin{tabular}{|c|c|c|c|c|c|c|c|c|c|}
\hline Scale & $N$ & Mean (SD) & Min & Q1 & Median & Q3 & $\operatorname{Max}$ & Floor & Ceiling \\
\hline \multicolumn{10}{|l|}{ Left eye } \\
\hline Symp-6 & 3157 & $74.1(21.9)$ & 0 & 62.5 & 79.2 & 91.7 & 100 & 0.2 & 18.4 \\
\hline Burning/smarting/stinging & 3137 & $70.8(35.1)$ & 0 & 50.0 & 100 & 100 & 100 & 5.8 & 55.6 \\
\hline Tearing & 3121 & $77.3(32.4)$ & 0 & 50.0 & 100 & 100 & 100 & 4.6 & 63.5 \\
\hline Dryness & 3123 & $77.4(32.8)$ & 0 & 50.0 & 100 & 100 & 100 & 4.6 & 64.5 \\
\hline Itching & 3126 & $73.1(32.9)$ & 0 & 50.0 & 100 & 100 & 100 & 4.5 & 56.2 \\
\hline Soreness/tiredness & 3126 & $71.9(33.7)$ & 0 & 50.0 & 100 & 100 & 100 & 4.4 & 55.4 \\
\hline Feeling of something in eye & 3120 & $74.6(33.0)$ & 0 & 50.0 & 100 & 100 & 100 & 4.6 & 59.4 \\
\hline Func-4 & 3152 & $75.9(24.1)$ & 0 & 62.5 & 81.3 & 100 & 100 & 0.4 & 31.5 \\
\hline Blurry/dim vision & 3119 & $71.5(34.3)$ & 0 & 50.0 & 100 & 100 & 100 & 6.2 & 55.3 \\
\hline Hard to see in daylight & 3122 & $78.5(34.7)$ & 0 & 50.0 & 100 & 100 & 100 & 7.7 & 69.7 \\
\hline Hard to see in darkness & 3124 & $74.0(36.0)$ & 0 & 50.0 & 100 & 100 & 100 & 8.9 & 62.8 \\
\hline Halos around lights & 3119 & $79.7(31.2)$ & 0 & 50.0 & 100 & 100 & 100 & 3.7 & 67.1 \\
\hline GSS total & 3157 & $74.9(19.8)$ & 2.5 & 62.5 & 77.8 & 90.0 & 100 & 0.1 & 11.0 \\
\hline \multicolumn{10}{|l|}{ Right eye } \\
\hline Symp-6 & 3156 & $74.1(22.0)$ & 0 & 62.5 & 79.2 & 91.7 & 100 & 0.3 & 18.5 \\
\hline Burning/smarting/stinging & 3132 & $71.0(35.3)$ & 0 & 50.0 & 100 & 100 & 100 & 6.2 & 56.1 \\
\hline Tearing & 3128 & $77.0(32.9)$ & 0 & 50.0 & 100 & 100 & 100 & 5.3 & 63.5 \\
\hline Dryness & 3117 & $77.3(32.8)$ & 0 & 50.0 & 100 & 100 & 100 & 4.7 & 64.4 \\
\hline Itching & 3126 & $73.1(33.0)$ & 0 & 50.0 & 100 & 100 & 100 & 4.5 & 56.2 \\
\hline Soreness/tiredness & 3125 & $71.5(33.8)$ & 0 & 50.0 & 100 & 100 & 100 & 4.5 & 54.9 \\
\hline Feeling of something in eye & 3115 & $75.0(32.9)$ & 0 & 50.0 & 100 & 100 & 100 & 4.6 & 59.9 \\
\hline Func-4 & 3153 & $75.8(24.4)$ & 0 & 62.5 & 81.3 & 100 & 100 & 0.4 & 31.6 \\
\hline Blurry/dim vision & 3127 & $71.6(34.4)$ & 0 & 50.0 & 100 & 100 & 100 & 6.5 & 55.6 \\
\hline Hard to see in daylight & 3128 & $78.1(35.0)$ & 0 & 50.0 & 100 & 100 & 100 & 7.9 & 69.1 \\
\hline Hard to see in darkness & 3125 & $74.1(35.9)$ & 0 & 50.0 & 100 & 100 & 100 & 8.6 & 62.8 \\
\hline Halos around lights & 3129 & $79.3(31.4)$ & 0 & 50.0 & 100 & 100 & 100 & 3.8 & 66.5 \\
\hline GSS total & 3156 & $74.8(20.0)$ & 2.5 & 62.5 & 100 & 90.0 & 100 & 0.1 & 10.6 \\
\hline \multicolumn{10}{|l|}{ Left + right eyes } \\
\hline GSS Symp-6 & 3161 & $74.1(21.2)$ & 0 & 62.5 & 78.6 & 91.7 & 100 & 0.2 & 14.8 \\
\hline GSS Func-4 & 3160 & $75.8(23.4)$ & 0 & 62.5 & 81.3 & 100 & 100 & 0.3 & 28.3 \\
\hline GSS total & 3161 & $74.8(19.2)$ & 2.5 & 62.5 & 78.8 & 90.0 & 100 & 0.1 & 8.4 \\
\hline
\end{tabular}

$\mathrm{SD}=$ Standard deviation; Min = minimum value; $\mathrm{Max}=$ maximum value; $\mathrm{Q} 1=25$ th percentile; $\mathrm{Q} 3=75$ th percentiles.

patients treated for glaucoma using the NEI-VFQ-25 and GSS instruments. Twenty-one of the 50 clinical centres caring for the currently diagnosed 500000 patients with POAG participated in this study, enrolling 3229 patients. Although the number of patients from each geographical loca- tion is imbalanced, it does reflect the different population density and medical centre density throughout the country.

Three different types of QoL questionnaires can be used in a research setting similar to ours, including general health-related QoL, vision-related
QoL and specific glaucoma-related QoL. In our study, we opted for two QoL questionnaires: the NEI-VFQ-25 that evaluates the impact of visual disorders on a wide range of functional and self-perceived QoL domains, and the glaucoma-specific GSS that scores the gravity of the visual and non-visual 


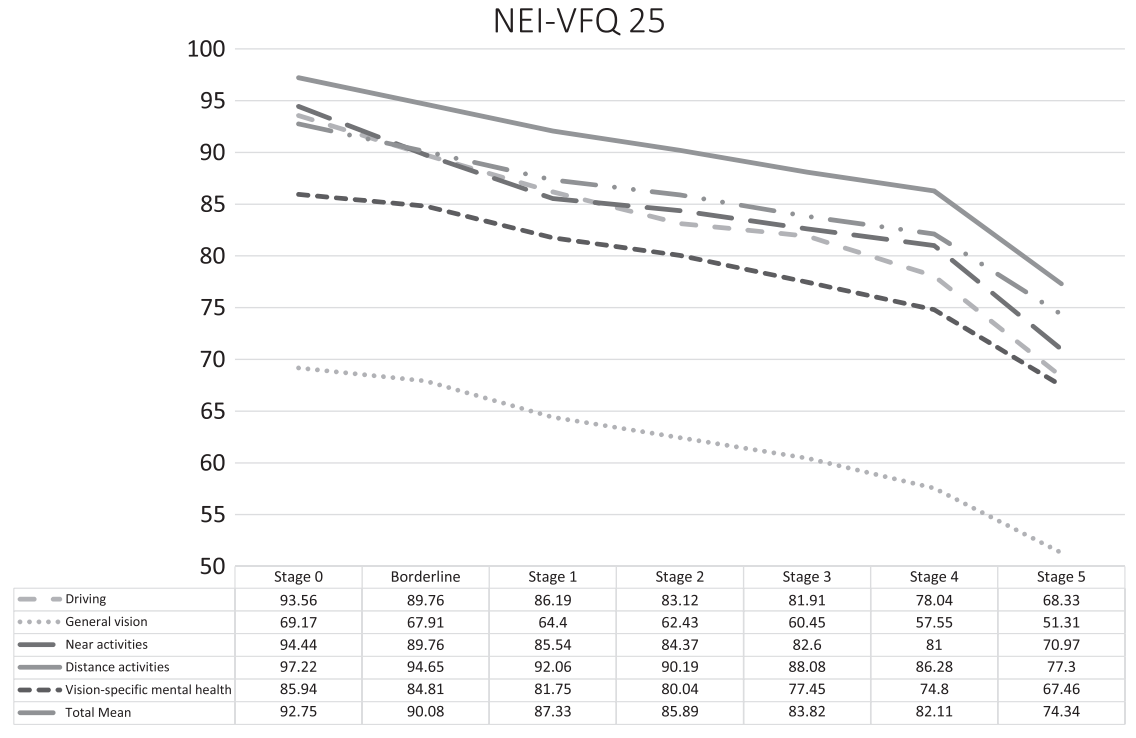

Fig. 2. NEI-VFQ 25 selected subscale mean scores according to glaucoma severity.

GSS

$$
100
$$

90

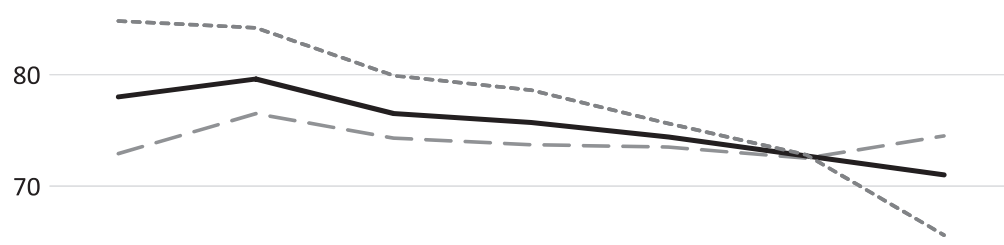

60

50

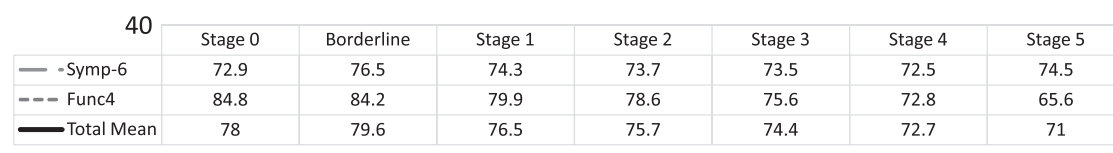

Fig. 3. GSS total and selected subscale mean scores according to glaucoma severity.

Table 7. Spearman correlation between the GSS and the NEI-VFQ-25 scales for each eye.

\begin{tabular}{llll}
\hline & GSS Symp-6 total & GSS Func-4 total & GSS Total \\
\hline NEI-VFQ 25 & & & \\
General health & 0.258 & 0.240 & 0.292 \\
General vision & 0.248 & 0.408 & 0.370 \\
Ocular pain & 0.624 & 0.417 & 0.618 \\
Near activities & 0.330 & 0.483 & 0.460 \\
Distance activities & 0.328 & 0.533 & 0.483 \\
Vision-specific social functioning & 0.235 & 0.392 & 0.351 \\
Vision-specific mental health & 0.320 & 0.411 & 0.418 \\
Vision-specific role difficulties & 0.334 & 0.456 & 0.453 \\
Vision-specific dependency & 0.224 & 0.362 & 0.329 \\
Driving & 0.249 & 0.491 & 0.410 \\
Colour vision & 0.184 & 0.324 & 0.287 \\
Peripheral vision & 0.266 & 0.452 & 0.403 \\
Total mean & 0.454 & 0.592 & 0.600 \\
\hline
\end{tabular}

signs and symptoms of this disease. Both instruments are self-administered and have been fully validated in Italian (Rossi et al. 2003, 2013).

The analysed patient sample had mild/moderate glaucoma (median mean deviation: $-3.90 \mathrm{~dB}$, median visual field index: 93\%); only about a third of the participants $(32.2 \%)$ had advanced glaucoma (stage 4 or 5).

Questionnaire acceptability among survey participants was excellent both for GSS and for NEI-VFQ-25. The percentage of missing item-level responses was always below $1.7 \%$, with the exception of the driving subscale of NEI-VFQ-25, presumably due to the large proportion of non-drivers among study participants.

Overall, HRQoL appeared to be well maintained in our population with mean scores $>70$ in most dimensions, except for general vision and general health. This finding reflects the fact that most of our participants had mild glaucoma and confirms previous findings that vision-related QoL remains relatively intact as long as visual fields are not severely affected (McKeanCowdin et al. 2008; Labiris et al. 2010; Onakoya et al. 2012; Wolfram et al. 2013).

Vice versa, the lower scores on general health and vision dimensions may be due to the advanced age of the studied population (mean: 66.9, SD: 12.1 years) or due to the fact that glaucomatous damage per se can be associated with a reduction in general health-related QoL. Wändell et al. (1997) used the generic QoL instrument-Swedish Health-Related Quality of Life Survey and observed that, compared to controls, glaucoma patients with moderate calculated binocular visual field defects had significantly lower scores in 2 of 13 general health and functioning subscales.

Notwithstanding the good overall results, HRQoL mean total scores, as well as scores on most subscales of both instruments, showed a significant inverse association with disease severity expressed by the Glaucoma staging system. van Gestel et al. (2010) showed a similar trend in their cross-sectional study of 537 ocular hypertension and POAG patients. Their study found a relationship between MD and HRQoL that was independent of patient demographics, visual acuity, medication adverse events and surgery. 
We performed correlation analysis of the two study instruments using the Pearson's correlation coefficient. Specific GSS subscales showed correlation with NEI-VFQ-25 subscales designed to capture similar constructs, but did not correlate with subscales describing different HRQoL domains. This suggests that the two questionnaires give complementary, but not overlapping, information on vision-related QoL of patients with POAG.

To the best of our knowledge, the current study represents the largest investigation on this subject. Many of the studies on QoL in glaucoma were conducted in significantly smaller samples. Moreover, as some of these were designed for the validation of instruments or their translated versions, rather than the characterization of vision-related QoL, limited attention was paid to the representativeness of the patient populations (Janz et al. 2001; Mangione et al. 2001; Rossi et al. 2003, 2013; Uenishi et al. 2003; Labiris et al. 2008, 2010; McKeanCowdin et al. 2008; Wang et al. 2008; Yamagishio et al. 2009; Lin \& Yang 2010; Hirneiss et al. 2011; Sawada et al. 2011; Mbadugha et al. 2012; Onakoya et al. 2012; Wolfram et al. 2013; Zhou et al. 2013a,b). The large sample size and wide geographical distribution suggest that study results may be representative for the Italian population of patients treated for POAG. However, we are unable to exclude a selection bias towards patients with less severe disease and better preserved HRQoL as information on individuals who refused participation was not collected. Our sample cannot be considered representative in a strict methodological sense, because the practical means of ensuring 'representativeness' (i.e. random inclusion from a central nationwide registry) are not available. However, this sample is as close as pragmatically possible to being representative by virtue of its wideranging geographical distribution, origin from diverse academic and nonacademic centres, and size. Furthermore, it is possible that not all included participants are necessarily patients with glaucoma. Just as is typical in most clinical centres, however, these 'suspects' are managed in a fashion similar to patients with glaucoma.

Another possible limitation of the present study is that it focuses on visual and daily function, rather than general health and psychological well-being aspects of QoL. This was mainly due to the unavailability of validated Italian versions of questionnaires assessing general health and psychological attributes of QoL. However, our common experience as members of the Italian Study Group on QoL in Glaucoma is that visual and functional symptoms are major determinants of a patient's subjective well-being. This notion is supported by the results of a recent study (Skalicky \& Goldberg 2008), which showed depression in patients with glaucoma was associated with increasing disease severity.

In summary, this study indicated that self-administered HRQoL instruments are acceptable to patients and provide detailed information on the clinical burden of glaucoma and its effects on visual loss, daily functioning and other dimensions of HRQoL. Overall, patient well-being can be preserved throughout the early and moderate stages of disease but will decline with progressive visual loss. These findings stress the importance of early diagnosis and timely and appropriate therapeutic approaches.

Further analyses are warranted to better characterize potential additional factors, which may interfere with HRQoL in patients with POAG and to evaluate vision-related functioning and well-being across different stages of the disease.

\section{References}

Baker M \& Winyard S (1998): Lost vision: older visually impaired people in the UK. London: RNIB.

Bonomi L, Marchini G, Marraffa M, Bernardi P, De Franco I, Perfetti S, Varotto A \& Tenna V (1998): Prevalence of glaucoma and intraocular pressure distribution in a defined population. The Egna-Neumarkt Study. Ophthalmology 105: 209-215.

Brusini P \& Filacorda S (2006): Enhanced Glaucoma Staging System (GSS 2) for classifying functional damage in glaucoma. J Glaucoma 15: 40-46.

Cedrone C, Mancino R, Cerulli A, Cesareo M \& Nucci C (2008): Epidemiology of primary glaucoma: prevalence, incidence, and blinding effects. Prog Brain Res 173: 3-14.

Cohen J (1988): Statistical power analysis for the behavioral sciences, 2nd edn. Hillsdale, NJ: Lawrence Erlbaum.

Dodds A (1991): The psychology of rehabilitation. Br J Vis Impair 9: 38-40.
European Glaucoma Society (2014): Terminology and guidelines for glaucoma, 4th edn. Savona: PubliComm Srl.

Giangiacomo A (2009): Glaucoma. Berlin, Heidelberg: Springer, 13-21.

Glen FC, Crabb DP \& Garway-Heath DF (2011): The direction of research into visual disability and quality of life in glaucoma. BMC Ophthalmol 11: 19.

Hinds A, Sinclair A, Park J, Suttie A, Paterson H \& Macdonald M (2003): Impact of an interdisciplinary low vision service on the quality of life of low vision patients. $\mathrm{Br} \mathbf{J}$ Ophthalmol 87: 1391-1396.

Hirneiss C, Vogel M, Kampik A, Neubauer AS \& Kernt M (2011): Measurement of glaucoma-specific functionality with the GQL-15 and correlation with parameters of visual function. Ophthalmologe 108: 939-946.

Janz NK, Wren PA, Lichter PR, Musch DC, Gillespie BW \& Guire KE (2001): Quality of life in newly diagnosed glaucoma patients: the collaborative initial glaucoma treatment study. Ophthalmology 108: 887-897; discussion 898 .

Kwon YH, Fingert JH, Kuehn MH \& Alward WL (2009): Primary open-angle glaucoma. N Engl J Med 360: 1113-1124.

Labiris G, Katsanos A, Fanariotis M, Tsirouki T, Pefkianaki M, Chatzoulis D \& Tsironi E (2008): Psychometric properties of the Greek version of the NEI-VFQ 25. BMC Ophthalmol 8: 4 .

Labiris G, Katsanos A, Fanariotis M, Zacharaki F, Chatzoulis D \& Kozobolis VP (2010): Vision-specific quality of life in Greek glaucoma patients. J Glaucoma 19: 39-43.

Lee BL, Gutierrez P, Gordon M, Wilson MR, Cioffi GA, Ritch R, Sherwood M \& Mangione CM (1998): The glaucoma symptom scale. A brief index of glaucoma-specific symptoms. Arch Ophthalmol 116: 861-866.

Lin JC \& Yang MC (2010): Correlation of visual function with health-related quality of life in glaucoma patients. J Eval Clin Pract 16: $134-140$.

Mangione CM, Lee PP, Gutierrez PR, Spritzer K, Berry S \& Hays RD (2001): Development of the 25-item national eye institute visual function questionnaire. Arch Ophthalmol 119: 1050-1058.

Mbadugha CA, Onakoya AO, Aribaba OT \& Akinsola FB (2012): A comparison of the NEIVFQ25 and GQL-15 questionnaires in Nigerian glaucoma patients. Clin Ophthalmol 6: 1411-1419.

McKean-Cowdin R, Wang Y, Wu J, Azen SP \& Varma R (2008): Impact of visual field loss on health-related quality of life in glaucoma: the Los Angeles Latino Eye Study. Ophthalmology 115: 941-948 el.

Mills T, Law SK, Walt J, Buchholz P \& Hansen J (2009): Quality of life in glaucoma and three other chronic diseases: a systematic literature review. Drugs Aging 26: 933950 .

Odberg T, Jakobsen JE, Hultgren SJ \& Halseide R (2001a): The impact of glaucoma on the quality of life of patients in Norway. I. 
Results from a self-administered questionnaire. Acta Ophthalmol Scand 79: 116-120.

Odberg T, Jakobsen JE, Hultgren SJ \& Halseide R (2001b): The impact of glaucoma on the quality of life of patients in Norway. II Patient response correlated to objective data. Acta Ophthalmol Scand 79: 121-124.

Onakoya AO, Mbadugha CA, Aribaba OT \& Ibidapo OO (2012): Quality of life of primary open angle glaucoma patients in Lagos, Nigeria: clinical and sociodemographic correlates. J Glaucoma 21: 287-295.

Quigley HA (2011): Glaucoma. Lancet 377: 1367-1377.

Rossi GC, Milano G \& Tinelli C (2003): The Italian version of the 25-item National Eye Institute Visual Function Questionnaire: translation, validity, and reliability. J Glaucoma 12: 213-220.

Rossi GC, Pasinetti GM, Scudeller L et al. (2013): The Italian version of the Glaucoma Symptom Scale Questionnaire: translation, validation, and reliability. J Glaucoma 22: 44-51.

Sawada H, Fukuchi F \& Abe H (2011): Evaluation of the relationship between quality of vision and the visual function index in Japanese glaucoma patients. Graefes Arch Clin Exp Ophthalmol 249: 17211727

Skalicky S \& Goldberg I (2008): Depression and quality of life in patients with glaucoma: a cross-sectional analysis using the Geriatric Depression Scale-15, assessment of function related to vision, and the Glaucoma Quality of Life-15. J Glaucoma 17: 546-551.

Spaeth G, Walt J \& Keener J (2006): Evaluation of quality of life for patients with glaucoma. Am J Ophthalmol 141: S3-S14.

Stuck AE, Walthert JM, Nikolaus T, Bula CJ, Hohmann C \& Beck JC (1999): Risk factors for functional status decline in communityliving elderly people: a systematic literature review. Soc Sci Med 48: 445-469.

Topouzis F, Coleman AL, Harris A et al. (2008): Factors associated with undiagnosed open-angle glaucoma: the Thessaloniki Eye Study. Am J Ophthalmol 145: 327-335.

Uenishi Y, Tsumura H, Miki T \& Shiraki K (2003): Quality of life of elderly Japanese patients with glaucoma. Int $\mathbf{J}$ Nurs Pract 9: 18-25.

van Gestel A, Webers CA, Beckers HJ, van Dongen MC, Severens JL, Hendrikse F \& Schouten JC (2010): The relationship between visual field loss in glaucoma and health-related quality-of-life. Eye (Lond) 24: 1759-1769.

Varma R, Richman EA, Ferris FL 3rd \& Bressler NM (2010): Use of patient-reported outcomes in medical product development: a report from the $2009 \mathrm{NEI} / \mathrm{FDA}$ Clinical Trial Endpoints Symposium. Invest Ophthalmol Vis Sci 51: 6095-6103.

Wandell PE, Lundstrom M, Brorsson B \& Aberg H (1997): Quality of life among patients with glaucoma in Sweden. Acta Ophthalmol Scand 75: 584-588.
Wang CW, Chan CL \& Jin HY (2008): Psychometric properties of the Chinese version of the 25-item National Eye Institute Visual Function Questionnaire. Optom Vis Sci 85: 1091-1099.

Wolfram C, Lorenz K, Breitscheidel L, Verboven Y \& Pfeiffer N (2013): Health- and vision-related quality of life in patients with ocular hypertension or primary open-angle glaucoma. Ophthalmologica 229: 227-234.

Yamagishio K, Keiji Y, Kimura T, Yamabayashi S \& Katsushima H (2009): Quality of life evaluation in elderly normal tension glaucoma patients using the Japanese version of VFQ-25. Nihon Ganka Gakkai Zasshi 113: 964-971.

Zhou C, Qian S, Wu P \& Qiu C (2013a): Anxiety and depression in Chinese patients with glaucoma: sociodemographic, clinical, and self-reported correlates. J Psychosom Res 75: 75-82.

Zhou C, Yao J, Qian S \& Wu P (2013b): Linguistic and psychometric validation of the Chinese version of the Glaucoma Quality of Life-15 (GQL-15-CHI): a cross-sectional study. Health Qual Life Outcomes 11: 188.

\section{Appendix Italian Study Group on QoL in glau- coma}

The following persons participated in this study and are to be considered coauthors: Co-ordinating Data Centre: Laboratorio di Ricerca Clinica, IRCCS Istituto di Ricerche Farmacologiche 'Mario Negri', Milano; Statisticians: IF, ER, A. Roberto; Administrative: E. Rulli; Informatics Support: L. Clivio, DP, F. Galli, L. Carlucci; Investigators: Università degli Studi di Brescia, Brescia (206 patients (pts)): LQ, AK, I. Riva, L. Delcassi; Università degli Studi 'Magna Graecia', Catanzaro (409 pts): LV, T. Carchedi, S. Talarico; A.O.U. Senese Ospedale Santa Maria delle Scotte, Università di Siena, Siena (337 pts): PF, I. Motolese, S. A. Bagaglia; Fondazione IRCCS Istituto di Ricovero e Cura a Carattere Scientifico Policlinico San Matteo, Pavia (293 pts): GCMR, S. Lanteri, L. Bossolesi; IRCCS Istituto di Ricovero e Cura a Carattere Scientifico Istituto Auxologico Italiano (265 pts): LC; Università degli Studi di Torino, Torino (253 pts): TR, R. Piccini; Fondazione IRCCS Istituto di Ricovero e Cura a Carattere Scientifico Ca' Granda Ospedale Maggiore Policlinico, Milano (205 pts): RR, A. Rossi; A.O.U. di Parma, Parma (200 pts): SG,
V. Tagliavini, N. Ungaro; A.O.U. Cagliari - Ospedale Civile San Giovanni di Dio, Cagliari (183 pts): MF, A. Cuccu, I. Zucca; A.O.U. 'Policlinico Vittorio Emanuele' P.O. Gaspare Rodolico, Catania (126 pts): MU, E. Bonacci, G. Cardarella; A.O.U. 'Ospedale Maggiore', Trieste (114 pts): D. Tognetto, O. Vattovani, P. Vallon, F. Iannacone; A.O. Arcispedale Santa Maria Nuova-IRCCS, Reggio Emilia (107 pts): L. Fontana, S. Marchi; Università Tor Vergata, Fondazione Policlinico Tor Vergata, Roma (100 pts): G.L. Manni, D. Jannetta, G. Roberti; A.O. S. Paolo, Milano (100 pts): L. Rossetti, E. Maggiolo, O. Oneta; A.O.U. Policlinico, Bari (99 pts): C. Sborgia, F. Cantatore; Ospedale Clinicizzato SS. Annunziata, Chieti (64 pts): L. Mastropasqua, L. Agnifili; A.O.U. Policlinico S. Orsola Malpighi, Bologna (36 pts): E. Campos, C. Gizzi, G. Giannaccare; A.O. di Desenzano del Garda, Desenzano del Garda (BS) (30 pts): V. Pucci, M. Cassamali; Dipartimento SPES Università del Molise Campobasso (20 pts): C. Costagliola; IRCCS AOU San Martino - IST, Genova (14 pts): C. Traverso, R. Scotto, M. Musolino, L. Landi, A. Bagnis.

Received on July 24th, 2014.

Accepted on August 22nd, 2015.

\section{Correspondence:}

Irene Floriani

IRCCS Istituto di Ricerche Farmacologiche 'Mario Negri'

Via La Masa 19 - 20156 Milano

Italy

Tel: +390239014695

Fax: + 390233200231

Email: irene.floriani@marionegri.it

The authors are responsible for the content and writing of the manuscript. The authors thank the study subjects for their participation.

IF, LQ, LH, AK, LV, PF, GCMR, LC, TR, RR, SG, MF, MU, ER, DP and FG were involved in the design and conduct of the study. IF, LQ, LH, ER, DP participated in collection, management, analysis and interpretation of the data. IF, LQ, LH, AK, LV, PF, GCMR, LC, TR, RR, SG, MF, MU, $\mathrm{ER}, \mathrm{DP}$ and $\mathrm{FG}$ were involved in preparation, review or approval of the manuscript.

The study was supported by an unrestricted grant of Associazione Italiana Studio del Glaucoma (AISG). 